\title{
EFEITOS METAFÓRICOS E GRAUS DE PRESENÇA DA ENUNCIAÇÃO NO ENUNCIADO
}

\author{
José Américo Bezerra SARAIVA* \\ Ricardo Lopes LEITE ${ }^{* *}$
}

- RESUMO: Este artigo assume como referencial teórico os postulados da Semiótica Discursiva, mormente na sua versão Tensiva (FONTANILLE; ZILBERBERG, 2001; FONTANILLE, 1998), que concebe o discurso como um campo de presença dotado de um centro sensível e de horizontes a partir dos quais as grandezas semióticas são moduladas em termos de presença e ausência, ou seja, um campo no qual as grandezas se tonificam ou se atonizam em relação a uma instância de natureza proprioceptiva. Nosso objetivo é analisar três notas jornalísticas com o propósito de acompanhar as modulações da presença da enunciação no enunciado. Supomos inicialmente que estas modulações promovem a tensão entre isotopias concorrentes, repercutem no grau de sua profundidade e, nestas notas, especificamente, geram um efeito metafórico graduável em termos de modo de existência semiótica. Os exemplos analisados mostram a necessidade de adotar um tratamento mais complexo para as relações entre enunciação e enunciado, sobretudo se quisermos levar em consideração a tensão entre estas duas instâncias, sempre regulada pelos modos de existência semiótica.

- PALAVRAS-CHAVE: Enunciação. Tensividade. Profundidade. Metáfora.

\section{Introdução}

A Semiótica atual explora o discurso especialmente como ato, pura atividade enunciativa, pelo qual se constituem tanto o sujeito-enunciante quanto o objeto-enunciado, conforme assevera Landowski (1992, p.167, grifo do autor) em interessante formulação: " [...] a 'enunciação' não será, pois, nada mais, porém nada menos tampouco, que o ato pelo qual o sujeito faz o sentido ser, correlativamente, o 'enunciado' realizado e manifestado aparecerá, na mesma perspectiva, como o objeto cujo sentido faz o sujeito ser."

Com base nesta formulação, empreendemos a tarefa de analisar três notas jornalísticas que permitem acompanhar o processo enunciativo, flagrando as

\footnotetext{
* UFC - Universidade Federal do Ceará. Centro de Humanidades - Departamento de Letras Vernáculas. Fortaleza - CE - Brasil. 60020-181 - jabsaraiva@gmail.com

** UFC - Universidade Federal do Ceará. Centro de Humanidades - Departamento de Letras Vernáculas. Fortaleza - CE - Brasil. 60020-181- rleite32@hotmail.com
} 
modulações da presença das grandezas em discurso para ele convocadas, principalmente no que tange à sintaxe e à semântica discursivas. Interessa-nos descrever não apenas os graus de presença da enunciação no enunciado, mas também a concorrência entre isotopias, que, nas notas analisadas, fazem do discurso um campo de tensividade em que as grandezas se distribuem em termos de profundidade.

Cumpre assinalar que este agenciamento das profundidades enunciativa e isotópica concorrem para a geração de um efeito de sentido metafórico que, em cada nota, apresenta um estatuto semiótico particular se levarmos em conta seus modos de existência.

\section{$\mathrm{O}$ discurso em ato}

Antes de tudo, o discurso, segundo Fontanille e Zilberberg (2001) e Fontanille $(1998,1999)$, deve ser visto como campo de presença, isto é, como um campo posicional cujas propriedades fundamentais são: 1) o centro de referência; 2) os horizontes do campo; 3) a profundidade do campo ou a relação entre o centro e os horizontes; e 4) os graus de intensidade e extensidade que medem a profundidade do campo. Expliquemos.

No ato perceptivo, o centro do campo corresponde ao corpo sensível, núcleo de intensidade máxima e extensidade mínima. Lugar onde se opera a percepção, ele é a instância de cuja existência depende a expressão do mundo natural, mundo exterior, e os conteúdos a ela correlacionados, mundo interior. O centro do campo é, desse modo, o operador da função semiótica, isto é, da correlação entre expressão e conteúdo. Os horizontes do campo, por sua vez, demarcam os domínios da presença e da ausência, ou seja, os limites do campo, onde a intensidade é mínima e a extensidade, máxima.

Segue-se daí que o campo posicional é graduado em termos de densidade de presença. As grandezas próximas ao centro são mais intensas do que aquelas situadas na periferia do campo. Elas diferem apenas quanto ao grau de presença, por isso fala-se de co-presença de grandezas num dado campo posicional. Neste contexto, a ausência equivale à intensidade nula, isto é, ao que simplesmente não afeta o centro de referência. Em havendo algo situado no horizonte do campo cuja intensidade seja forte, abre-se, então, um novo campo de presença, com centro, horizontes e dinâmica tensiva respectivos.

Assim, tudo se passa como se uma dada grandeza, uma vez tendo atravessado o horizonte do campo, negando, desse modo, sua condição de ausente, se apresentasse como correlação entre uma intensidade preceptiva quase nula e certa extensidade. Na medida em que se aproxima do centro do campo, a grandeza percebida ganha em intensidade e perde em extensidade (isto é, perde distância 
com relação ao centro), criando um efeito de profundidade, que nada mais é do que a distância sensível entre o centro do campo e seus horizontes. Na verdade, este efeito de profundidade só pode ser sentido se houver uma mudança na tensão entre intensidade e extensidade, quer dizer, se houver movimento entre o centro e os horizontes, aproximações e afastamentos da grandeza com relação ao centro de referência.

O campo de percepção tem, pois, uma estrutura topológica e envolve, minimamente, as posições ocupadas por seus actantes: o sujeito da percepção e a presença do objeto percebido. Com o discurso não ocorre coisa diferente. Antes mesmo de ser entendido, o discurso se impõe, como campo de presença, à percepção do enunciatário. Neste momento, o discurso se apresenta como matéria para a percepção e como tal deve ser analisado. Isto é, o discurso deve ser encarado como objeto da percepção, pois, se o primeiro ato da instância do discurso é uma tomada de posição, como já admitimos, então, é a partir desta tomada de posição, entendida como ato enunciativo, que o mundo se faz presente por meio da linguagem, conforme assevera Fontanille (1998), retomando o axioma fenomenológico de Merleau-Ponty ${ }^{1}$.

Campo posicional que é, o discurso se apresenta para a instância enunciante dotado de profundidade. E tanto as grandezas presentes no discurso quanto a disposição delas com relação ao centro dêitico são efeitos do que Fontanille (1999) chama de presentificação. Esta presentificação, por sua vez, é tarefa da instância de discurso, que garante a presença dela no mundo ao cumprir as operações necessárias para sua realização, isto é, ao predicar. Por isto, o próprio da enunciação é o ato predicativo. É por meio da predicação que alguma coisa se faz presente, que o conteúdo de um enunciado se torna presente no campo do discurso.

Para Fontanille (1998), que neste ponto segue Coquet (1984, 1997), a enunciação, primeiramente, torna o enunciado presente pela asserção, ao predicar de modo irrefletido, sem assumir o ato. Em seguida, ela assume este ato e toma o enunciado como coisa presente para aquele que enuncia. Neste segundo ato, aquilo que o enunciado torna presente no campo posicional mantém com o ponto de referência, isto é, com a posição da instância discursiva, certa profundidade, esta medida em termos de correlação entre as categorias tensivas da intensidade e da extensidade.

Desse modo, a enunciação se constitui como um duplo ato de predicação. Como asserção, ato relacionado à presença dos enunciados no campo de presença do discurso, a predicação é dita "existencial". Neste caso, o enunciado

Trata-se do axioma "[...] perceber é tornar algo presente a si com a ajuda do corpo." (MERLEAU-PONTY apud FONTANILLE, 1998, p.97). 
se situa no campo posicional apresentando-se sempre dotado de um modo de existência próprio (real, atual, potencial e virtual), isto é, um grau de presença, apreendido como correlação entre intensidade e extensidade. Para fornecer um exemplo, consideremos o enunciado Pedro quer saber dançar, modalizado pelo querer e pelo saber. A ação de dançar apresenta-se aqui suspensa pela dupla modalização. Em Pedro dança, a ação está realizada. Já em Pedro sabe dançar, o que se realiza é o verbo cognitivo. E em Pedro quer saber dançar, é o verbo volitivo que se realiza, e a ação de dançar vê-se virtualizada, já que o querer de Pedro não pressupõe o saber nem a ação de dançar.

Como se pode ver, um dos efeitos da modalização aplicada a um processo é o de afastá-lo do centro do discurso, desfocalizando-o e colocando-o no plano de fundo, isto é, na periferia do campo. Em outros termos, o processo dançar perde intensidade e ganha profundidade, extensidade, quando se encontra modalizado. Assim, o número de modalizações altera o modo de existência do processo no campo de presença discursivo, jogando com as categorias tensivas de intensidade e extensidade. É, pois, pela asserção que um dado conteúdo enunciado é identificado como presença num dado campo discursivo.

Mas, para além do ato de asserção, a predicação se faz como assunção, ao relacionar-se diretamente com aquela. É por este ato que algo surge para a posição da instância de discurso afetando-a de algum modo. A assunção tem um caráter autorreferencial porque se engaja na asserção, assume a responsabilidade pelo enunciado e se apropria da presença do que surge no campo discursivo, tornando-se, assim, seu ponto de referência.

De acordo com esta concepção do ato predicativo, só podemos falar da diferença de presença discursiva de grandezas e, por conseguinte, dos gradientes dos modos de sua presença, se estas grandezas estiverem situadas no campo posicional da instância de discurso e se elas forem medidas em termos de proximidade-distância (e do movimento que conduz de uma à outra e vice-versa) em relação ao centro do discurso. Desse modo, o discurso passa a ser analisado na perspectiva da enunciação, ou seja, das operações que produzem a significação, e, portanto, como processo de produção e interpretação de sentido, discurso em ato, ou, numa palavra, como semiose.

Na perspectiva do discurso em ato, a presença passa a ser, então, a propriedade básica da instância de discurso responsável pela semiose. Como se disse, a instância do discurso, no ato de produção e interpretação do sentido, toma posição no campo de presença, que é, antes mesmo de um campo de exercício da capacidade de linguagem, um campo de presença sensível e perceptiva² ${ }^{2}$.

Em tese de doutorado, Saraiva (2008) mostra como a identidade do sujeito enunciante se forja como posição no campo de presença a partir das estratégias breantes. 


\section{Os mecanismos breantes}

Greimas e Courtés (2008, p.66) definem enunciação como "[...] uma instância linguística, logicamente pressuposta pela própria existência do enunciado." Para estes autores, a estrutura da enunciação comporta duas instâncias, a do enunciador e a do enunciatário, sincretizados num sujeito da enunciação.

Ora, como dissemos na introdução do artigo, é no fazer enunciativo que tanto o enunciado quanto o sujeito da enunciação são gerados. Portanto, se concebermos a enunciação como uma espécie de enunciado mais amplo (GREIMAS, 1974), o sujeito da enunciação, na produção do discurso, será o simulacro resultante do sincretismo de dois outros simulacros: o do enunciador e o do enunciatário. Além destes simulacros, o jogo enunciativo pode instaurar no discurso os actantes da enunciação enunciada, simulando, por debreagem, a enunciação propriamente dita.

Em seguida, os actantes da enunciação enunciada podem delegar a fala para outros actantes, que, por sua vez, podem fazer o mesmo com relação a outros actantes ainda, e assim por diante. Neste processo de debreagens sucessivas, acontece que toda enunciação simulada no interior de um discurso referencializa o simulacro da enunciação anterior, conferindo-lhe uma impressão de realidade. Mas, é bom que se diga, esta referencialização não passa de um efeito de discurso. Por isto é que podemos dizer que não lidamos, em discurso, senão com simulacros.

Aqui, cabe uma observação de caráter conceitual. Para Fiorin (1996), que neste ponto segue Greimas, a debreagem se biparte em debreagem enunciativa e debreagem enunciva. A primeira se configura quando, no ato de instalação do enunciado, projetam-se, nele, as categorias eu-aqui-agora; a segunda, quando se projetam as categorias ele-lá-então. A embreagem, por sua vez, se dá quando uma operação discursiva tem por efeito neutralizar estes dois conjuntos de categorias, quando um é usado em vez do outro, num dado contexto. Fiorin (1996) postula, igualmente, dois tipos de embreagem, a enunciativa e a enunciva, dependendo do conjunto de categorias em favor do qual se realiza a neutralização. No entanto, há autores, caso de Bertrand (2003), por exemplo, que já veem, na debreagem enunciativa, uma operação embreante, na medida em que a projeção das categorias eu-aqui-agora cria, por si mesma, o efeito de retorno à enunciação, ou seja, simula a enunciação no interior do enunciado. Neste artigo, optamos pela terminologia de Fiorin, pela simples razão de ter ele realizado um exaustivo trabalho acerca do assunto, com farta exemplificação: o seu As astúcias da enunciação.

Se a enunciação é o lugar de instauração do sujeito e se este é o ponto de referência das relações espácio-temporais, ela é o lugar do ego, hic et nunc, isto é, do eu, aqui e agora. Como a pessoa enuncia num dado espaço e num 
determinado tempo, todo espaço e todo tempo organizam-se em torno do "sujeito", tomado como ponto de referência. Assim, a enunciação é a instância constitutiva do enunciado, cujo centro, visto numa perspectiva puramente formal, é o eu que enuncia, num aqui e num agora. E o enunciado, por sua vez, é o estado resultante, independentemente de suas dimensões sintagmáticas, desta práxis enunciativa.

A instância enunciativa pode ser simulada no interior de um enunciado, criando-se assim ilusões enunciativas em que o eu enunciador assume papéis diferentes. Destarte, temos o par enunciador / enunciatário como actantes implícitos por figurarem como pressupostos do ato enunciativo; o par narrador / narratário, categorias projetadas no interior do enunciado, sujeitos da enunciação simulada no texto; e o par interlocutor / interlocutário, sujeitos que interagem num outro quadro enunciativo simulado pelo narrador. Vejamos o quadro abaixo adaptado de Barros (1988, p.75):

\section{Quadro 1: Instâncias Enunciativas}

\section{Implícitos (enunciação pressuposta)}

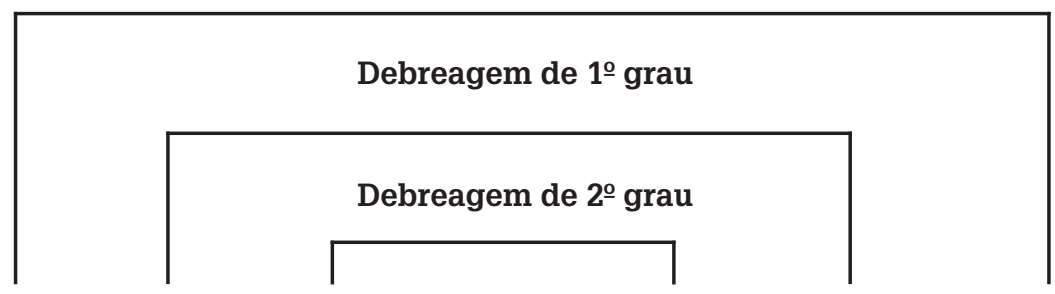

\{Enunciador Narrador \{Interlocutor \{Objeto\} Interlocutário\} Narratário\} Enunciatário\}

Fonte: Adaptado de Barros (1988, p.75).

Conforme se pode observar, o objeto-discurso se constitui no interior de um quadro enunciativo, que pode ser simulado, por debreagens de primeiro e segundo graus, no interior de outro quadro enunciativo, e assim sucessivamente, de modo que se simulam níveis de enunciação, dispostos hierarquicamente, no interior do qual o discurso-objeto deve ser analisado.

Sendo a enunciação um jogo de construção de simulacros, o processo comunicativo não pode ser, portanto, reduzido à mera circulação de mensagens num dado contexto, como sustentavam alguns adeptos da teoria da informação. A enunciação, examinada sob o prisma da narratividade, tem, no programa de persuasão-manipulação-interpretação intersubjetiva, próprio do processo comunicativo, a construção de simulacros como um dos procedimentos básicos. E o enunciado, por sua vez, não é apenas objeto de transmissão de saber, mas um objeto-discurso construído e manipulado pelo sujeito da enunciação. 
Veja-se bem que, mais uma vez, não é do sujeito "real" que se fala aqui, e o emprego do termo simulacro procura deixar isto claro, pois simular é um fazer-crer que envolve tanto o enunciado como a enunciação. Neste processo, portanto, são simulacros o sujeito da enunciação, o enunciador, o enunciatário etc.

Como ensina Barros (1988), em Semiótica, quando o enunciado é analisado na perspectiva de sua produção, pode-se compreender o sujeito da enunciação como um simulacro resultante do sincretismo entre enunciador e enunciatário. Mas, se o enunciado for examinado sob o ponto de vista da estrutura da comunicação, enunciador e enunciatário serão entidades discretas próprias da sintaxe comunicacional, em que o enunciador desempenha o papel de destinador-manipulador, e o enunciatário, o de destinatário-julgador da comunicação.

Tudo se passa, então, como se o sujeito da enunciação, ao produzir o enunciado, convocasse as estruturas semionarrativas virtuais para atualizá-las em discurso, e, neste processo de discursivização daquelas estruturas, ele assumisse o duplo papel actancial de enunciador e enunciatário. Mas, ao comunicar o discursoenunciado, o sujeito da enunciação se discretizasse e assumisse apenas o papel de enunciador, apresentando-se, neste caso, o processo de discursivização como um lugar de troca entre enunciador e enunciatário.

Dito de outro modo, o enunciador é o actante instaurado pelo simples ato de o sujeito da enunciação enunciar que, ao enunciar, constrói perspectivações das estruturas semionarrativas atribuídas àquele, considerado, por isso, seu responsável. Por outro lado, no mesmo ato, o sujeito da enunciação cria o enunciatário como lugar virtual cuja ocupação "efetiva" será obra do enunciatário que receberá o enunciado. Este processo, como vimos, pode ser simulado no interior do enunciado, dando origem a novas estruturas de comunicação pela instauração de novos actantes, actantes da enunciação enunciada, como, por exemplo: narrador / narratário e interlocutor / interlocutário.

O sincretismo dos papéis de enunciador e enunciatário evidencia-se, principalmente, em discursos sem narrador explícito, em que os acontecimentos são apresentados objetivamente, como se se desenvolvessem por si mesmos. Nestes discursos, constrói-se, com efeito, um único lugar de observação em que enunciador e enunciatário se encontram sincretizados ${ }^{3}$. Trata-se, nas palavras de Fontanille (1998), da figura de um observador, entendido como o agenciador dos pontos de vista que regulam os modos pelos quais o enunciado pode ser apreendido, e os pontos de vista são, para Fontanille (1998, p.177, tradução nossa), as perspectivações que exploram " [...] a orientação discursiva para fazer face à

Estratégia empregada, por exemplo, no discurso científico, em que enunciador e enunciatário sincretizam-se na figura do observador. 
imperfeição constitutiva de toda percepção."4 Noutros termos, trata-se de um recurso do qual o enunciador pode lançar mão para manipular o enunciatário, ao eleger um ponto de vista, generalizante ou particularizante, por exemplo, e ao simulá-lo no discurso, como sendo a sua própria posição de enunciação, posição esta fundamental para reconstruir-se a significação. Mas, repitamos, tanto o enunciador como o enunciatário são simulacros, construções discursivas, assim como o são os actantes do enunciado.

\section{Mecanismos breantes e efeito metafórico}

Os mecanismos enunciativos acima apresentados podem exercer uma função moduladora dos efeitos metafóricos, como veremos nos textos selecionados para análise. Não pretendemos promover uma discussão pormenorizada sobre a metáfora do ponto de vista semiótico. Se se quiser um estudo mais aprofundado do assunto, remetemos a Fontanille e Zilberberg (2001) e Fontanille (1998).

No entanto, para os propósitos deste artigo, é preciso assumir a metáfora como fenômeno discursivo e não somente como jogo de figuras, que envolve a interação entre teor e veículo, consoante as teorias clássicas. Na dimensão discursiva, cabe falar não em metáfora propriamente dita, mas em processo metafórico, porque, conforme Leite (2011), a metáfora passa a ser examinada no discurso em ato e, assim como toda grandeza semiótica, ao penetrar no espaço tensivo do discurso, ela deve ser qualificada em termos de intensidade e extensidade.

Agora, vamos analisar três notas jornalísticas cujas modulações dos graus de presença da enunciação no enunciado promovem a tensão entre isotopias concorrentes, repercutem no grau de sua profundidade e geram efeitos metafóricos graduáveis em termos de modo de existência semiótica.

\section{PORTO}

Ana Maria Braga vai se desfazer de dois de seus três barcos. A apresentadora está procurando comprador para as lanchas Âmbar I, de 47 pés, e Âmbar II, de 52 pés. Ela pretende ficar apenas com Shambhala, o trawler de 85 pés que inclui até TV de tela plana na sala de estar. Lanchas com essas dimensões custam entre R\$450 mil e R\$600 mil. (BERGAMO, 2005).

Do ponto de vista narrativo, há neste texto um sujeito de estado em conjunção com um dado objeto-valor, figurativizado por três lanchas de variadas dimensões. Este sujeito está modalizado por um querer-fazer e apresenta-se num dispositivo modal que lhe confere a competência necessária para a realização deste fazer. Em

${ }_{4}$ No original: "[...] l'orientation discursive pour faire face à l'imperfection constitutive de toute perpecption." 
outras palavras, ele quer vender duas de suas três lanchas e conservar consigo a maior e mais bem equipada, portanto tria os objetos intensificando o valor de um deles, o trawler Shambhala. Esta triagem e esta intensificação são manifestadas pelas expressões "apenas" e "até" de claro teor argumentativo 5 .

Se quisermos convocar Benveniste (1991), estas duas expressões têm estatuto ambíguo no que concerne à distinção entre o que pertence preponderantemente ao plano do narrado (história) e ao do discurso, isto é, neste ponto do texto depreende-se uma projeção da enunciação no enunciado, muito embora não se constate nenhuma marca canônica de debreagem enunciativa. Na verdade, estas duas expressões estão dispostas de modo a estabelecer uma espécie de gradação no que tange à presença da enunciação no enunciado, ou seja, "até" tem um caráter mais enunciativo do que "apenas".

Como se vê, a estratégia adotada no texto consiste na descrição de um estado de coisa e de um fazer transformador, sobre a qual incide a avaliação do enunciador, cuja presença no enunciado insinua-se por meio das duas expressões mencionadas, ou seja, trata-se de uma presença ainda atualizada, em vias de realização. A realização desta presença, no entanto, não se efetiva completamente, sobretudo porque o último período do texto retoma a debreagem enunciva pelo uso da terceira pessoa ("lanchas com essas dimensões"), característica do plano do narrado, mas conserva ainda resquícios de debreagem enunciativa ("essas").

Isto tudo, em conjunto, borra a fronteira entre o que Benveniste chama de história e discurso ou, em termos semióticos, o plano do enunciado e o da enunciação. É interessante observar que esta estratégia de discursivização envolve o enunciatário num jogo de aproximação e distanciamento que finda por indeterminar seu estatuto enunciativo.

O ponto de partida do texto é o item lexical "porto", expressão compactada, que, como se sabe, consiste numa constelação figural virtualizada (GREIMAS, 1977), e o leitor não dispõe ainda de um percurso de leitura capaz de lhe fornecer o conteúdo isotopante do texto. À medida que o ato predicativo se desenvolve, o foco inicial "porto" começa a se constituir como objeto de apreensão na exata proporção em que a isotopia "marítima, fluvial ou lacustre" atualiza-se pela mediação das figuras "barcos", "lanchas", "pés" e "trawler". No entanto, o sema "requinte" já se insinua na descrição que envolve o número de barcos, suas dimensões e, principalmente, o aparelho de TV.

Neste ponto do texto, uma nova isotopia começa a se esboçar. Trata-se da isotopia que poderíamos chamar "poder econômico", diretamente ligada à ideia de "requinte". Este núcleo isotopante surge deslocando o núcleo anterior,

5 Este fenômeno nos remete às ideias pioneiras de Ducrot (1977) acerca da argumentação na língua e, especificamente, dos operadores argumentativos. 
"porto", do centro do discurso e passa a concorrer com ele. Na verdade, as duas isotopias coexistem no discurso e se apresentam em diferentes graus de profundidade, numa contínua tensão em que ora uma ora outra está fortemente visada $e$ fracamente apreendida. Mas nem uma nem outra isotopia se realiza completamente em discurso, isto é, nem uma nem outra se encontra fortemente visada e apreendida ao mesmo tempo.

Vale destacar que esta tensão contínua entre as duas isotopias não privilegia nenhuma, e dela decorre um efeito intraduzível nos termos das teorias clássicas da metáfora, ou seja, pela interação entre teor e veículo metafórico. No entanto, no discurso em ato, vemos pulsar uma metáfora, que equivaleria a dizer: Ana Maria Braga é um "porto" por ancorar muitos e caros barcos.

Passemos para outro exemplo.

\section{Aquário}

Lembram-se do procurador Luiz Francisco de Souza, aquele que vivia processando o governo Fernando Henrique Cardoso? Agora ele está quietinho e longe dos holofotes. Desde que voltou de Portugal, onde foi fazer uma especialização, submergiu e não se ouviu falar mais dele. (PASCOWITCH, 2005).

Do ponto de vista narrativo, neste texto temos um sujeito cujo estado juntivo se vê alterado. Antes de um fazer transformador, ele se define como sujeito de estado pela atividade que desenvolve, "vivia processando" ou, em forma substantiva, era um "processador". No momento da enunciação ("agora"), o estado deste sujeito se caracteriza pela inatividade, em oposição à intensa atividade anterior. Ora, o texto refere dois estados de coisa mediados por uma transformação, que podemos supor seja realizada pelo mesmo sujeito de estado. Então, não é descabido dizer que o texto tem como foco o fazer transformador (a atividade se transforma em inatividade) que coloca o procurador na periferia do campo de presença do enunciatário, porque ele cai na inatividade. Por isso, o texto principia pelo "lembram-se" interrogativo, que convoca para o campo discursivo a figura do procurador, evanescente no agora da enunciação, e faz referência ao estado anterior, "vivia processando", e ao estado atual, "está quietinho". E o texto faz tudo isto jogando com os graus de presença da enunciação no enunciado. Senão vejamos.

Se tomarmos a figura "aquário", debreada enuncivamente, como um primeiro gesto de afastamento das instâncias da enunciação e do enunciado, podemos admitir que se desenvolve no texto um jogo de aproximação/distanciamento dos actantes da enunciação (enunciador e enunciatário) com relação ao enunciado e suas figuras, sobretudo pelo concurso das expressões que seguem e que aparecem no texto alternadamente: "lembram-se" (aproximação); "aquele" (distanciamento); 
"agora" (aproximação); "longe" (distanciamento); "voltou" (aproximação) e "submergiu" (afastamento). Esta última figura merece especial atenção pelo fato de servir como conector das isotopias "sumiço do procurador" e aquela sugerida pela figura "aquário".

Mais interessante ainda é o efeito de perspectiva criado pelo verbo "submergir", que gera um ponto de observação em que o observador se situa necessariamente fora e acima do aquário, consoante a definição já dicionarizada deste verbo: "[...] fazer sumir ou ficar totalmente sumido, mergulhado na água; afundar." (HOUAISS; VILLAR, 2001). Acrescente-se o fato de "holofote" também servir de conector entre as referidas isotopias, pois tanto o procurador se afasta do campo de visão dos actantes da enunciação, isto é, do centro irradiador da luz ou, se preferirmos, da ribalta celebrizante da mídia, quanto um peixe se distancia do campo de visão do observador ao submergir, devido à menor incidência de luz embaixo d'água. Assim, um contínuo metafórico se estabelece entre "aquário", "holofote" e "submergiu".

Se comparadas as duas notas, uma constatação se impõe: as articulações entre enunciação e enunciado também podem ser estudadas em termos de existência semiótica, isto é, em termos de tonicidade/atonicidade da presença de elementos enunciativos no enunciado, fenômeno que mantém estreita relação com os graus de presença das isotopias concorrentes à realização. Isto se torna mais evidente quando nos deparamos com o exemplo seguinte.

\section{Espelho}

A Prefeitura de Maracanaú mantém há dois anos um laboratório de informática para portadores de necessidades especiais. São oito computadores com programas adaptados para deficientes auditivos, visuais e psicomotores, além de uma impressora em Braille. É uma ação que supera, e muito, os conceitos de inclusão digital. (MACIEL, 2007, p.4).

Para não fugirmos ao esquema analítico até aqui esboçado, comecemos pelo nível narrativo. O texto descreve um estado de coisa em que um sujeito ("portadores de necessidades especiais") se encontra conjunto com um objetovalor ("laboratório de informática"), estado este proporcionado por um sujeito do fazer ("Prefeitura de Maracanaú"). O objeto-valor é recoberto por figuras que atualizam o tema "adequação", ou seja, trata-se de computadores "adaptados" aos diferentes tipos de deficiência física, ou seja, narrativamente, a falta é liquidada.

Destaque especial é dado à "impressora em Braille" mediante um "além de" que introduz mais um elemento na enumeração figurativa do objeto-valor. No entanto, esta locução prepositiva já prenuncia a tonificação da presença do enunciador no enunciado. O período seguinte, "É uma ação que supera, e muito, os conceitos de inclusão digital", acentua esta presença e, ao mesmo tempo, 
funciona como elemento isotopante com relação ao título "espelho", até então uma icógnita. A inserção da enunciação no enunciado, já prenunciada pelo "além de", se intensifica com o emprego do verbo valorativo "supera" e recrudesce com a clara intervenção do enunciador manifestada pela expressão "e muito".

Neste momento, o título passa a fazer sentido por conta da isotopia sugerida pelo último período: "exemplo a ser seguido", que confere ao texto um sutil efeito irônico, se tomarmos como pauta para a interpretação as fraseologias que podem ser resumidas assim: "espelhe-se nisto", "que isto lhe sirva como exemplo", apenas atualizadas.

Então, se compararmos esta última nota com as duas anteriores, fácil é perceber que as três podem ser dispostas num esquema tensivo de correlação inversa entre os graus de presença da enunciação no enunciado e a tensão entre as isotopias concorrentes, conforme o gráfico abaixo.

\section{Gráfico 1: Gráfico tensivo}

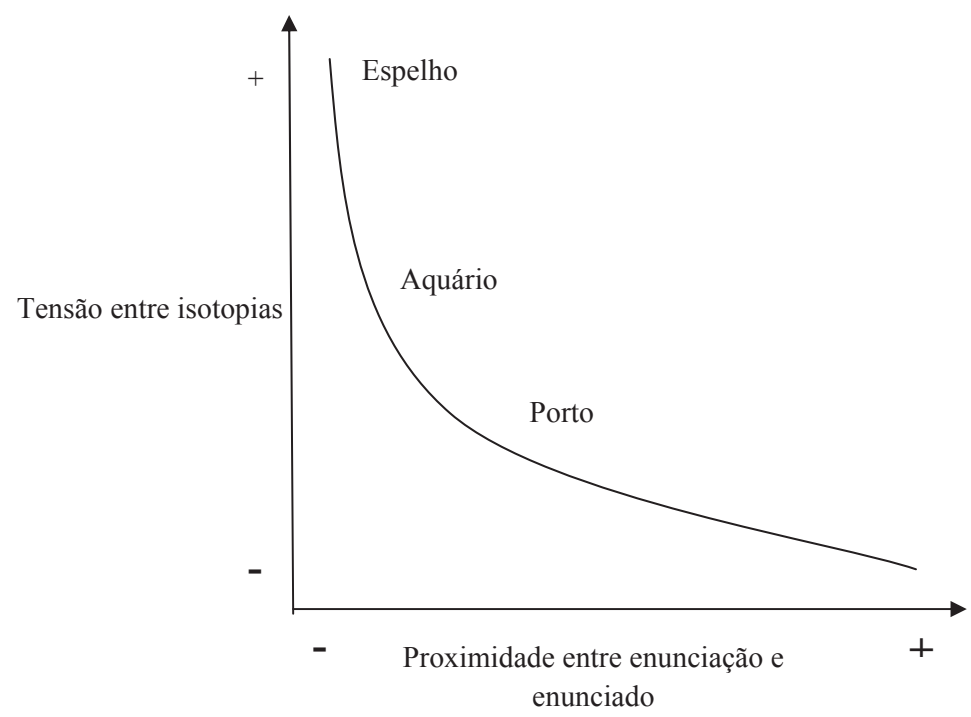

Fonte: Elaboração própria.

Como se vê, as três notas podem ser organizadas em função da relação inversa entre a tensão das isotopias e os graus de proximidade da enunciação com relação ao enunciado. Assim, em "Porto" há maior proximidade entre as duas instâncias discursivas e menor tensão entre as isotopias concorrentes ("marítima, fluvial ou lacustre" e "poder econômico"), ao passo que "Aquário" situa-se numa zona entre "Porto" e "Espelho", pois apresenta uma oscilação entre proximidade e distanciamento destas instâncias e entre graus de tensão das isotopias ("aquário" 
e "sumiço do procurador"). Já em "Espelho", ocorre o recrudescimento da tensão entre as isotopias ("espelho" e "exemplo a ser seguido") pari passu ao afastamento da enunciação com relação ao enunciado.

O gráfico representa apenas parte do complexo fenômeno tensivo, pois, se quiséssemos graduar a intensidade da presença do sentido metafórico em cada nota, teríamos que considerar os graus de profundidade de cada isotopia no que concerne à sua realização. Por exemplo, em "Espelho" a isotopia metafórica "exemplo a ser seguido" não se presta tão facilmente à interpretação quanto a isotopia metafórica de "Porto", "poder econômico", pois o grau de presença de cada uma varia em termos de profundidade discursiva, mesmo que tenhamos admitido estar o sentido metafórico de cada nota em particular fortemente visado mas fracamente apreendido.

\section{Palavras finais}

Os exemplos analisados mostram a necessidade de adotar um tratamento mais complexo para as relações entre enunciação e enunciado, sobretudo se quisermos levar em consideração a tensão entre estas duas instâncias, sempre regulada pelos modos de existência semiótica.

Como vimos, os graus de presença da enunciação no enunciado em cada nota, ao gerar os efeitos de sentido de aproximação e afastamento, promovem a tensão entre as isotopias concorrentes. Mas estas isotopias não surgem por intermédio de um desencadeador nem de um conector claramente manifestado, como é comum nas clássicas análises das figuras retóricas. Na verdade, a interpretação das metáforas das notas analisadas resiste ao trabalho do leitor, porque a fase da resolução do conflito isotópico fica em suspenso, e o sentido metafórico permanece apenas atualizado.

Trata-se, com efeito, de graus diferentes de atualização, pois não podemos dizer que o sentido metafórico se atualiza de modo igual nas três notas. Queremos crer, com base no que diz Fontanille (1998), que há uma fase intermediária entre a confrontação (colocação em presença entre duas ou mais isotopias) e a resolução, decorrente das variações da assunção enunciativa, ou, em nossos termos, dos graus de presença da enunciação no enunciado.

SARAIVA, J. A. B.; LEITE, R. L. Utterance's metaphorical effects and presence degrees in a sentence. Alfa, São Paulo, v.57, n.1, p.37-51, 2013.

- ABSTRACT: This paper's theoretical framework concerns the Discourse Semiotics' assumptions, primarily its Tensive version (FONTANILLE; ZILBERBERG, 2001; FONTANILLE, 1998), which conceives the discourse as a field of presence, endowed with 
a sensitive core and horizons from which semiotic magnitudes are modulated in terms of presence and absence, i.e. a field in which magnitudes become tonic or atony regarding a proprioceptive nature instance. Our goal is to analyze three newspaper notes in order to monitor utterance presence modulations in a sentence. This study initially assumes that those modulations promote tension between co-occurring isotopies, impact their degree of depth, and specifically in these notes, they cause a gradable metaphoric effect in terms of semiotic existence mode. Examples analyzed here show the need for adopting a more complex treatment for relationships between utterance and sentence, mainly if one desires to consider the tension between both instances - always governed by semiotic existence modes.

- KEYWORDS: Utterance. Tensivity. Depth. Metaphor.

\section{REFERÊNCIAS}

BARROS, D. L. P. Teoria do discurso: fundamentos semióticos. São Paulo: Atual, 1988.

BENVENISTE, E. Problemas de lingüística geral I. Campinas: Pontes, 1991.

BERGAMO, M. Porto. Folha de São Paulo, São Paulo, 06 maio 2005. Mlustrada. Disponível em: <http://www1.folha.uol.com.br/fsp/ilustrad/fq0605200509.htm>. Acesso em: 13 mar. 2010.

BERTRAND, D. Caminhos da semiótica literária. Bauru: EDUSC, 2003.

COQUET, J-C. La quête du sens: le langage en question. Paris: Universitaires de France, 1997.

. Le discours e son sujet. Paris: Klincksieck, 1984. v.1.

DUCROT, O. Princípios de semântica linguística. São Paulo: Cultrix, 1977.

FIORIN, J. L. As astúcias da enunciação. São Paulo: Ática, 1996.

FONTANILLE, J. Point de vue: perception et signification. In: FONTANILLE, J. Semiótique et literature: essais de méthode. Paris: PUF, 1999. p.41-61.

Sémiotique du discours. Limoges: Pulim, 1998.

FONTANILLE, J.; ZILBERBERG, C. Tensão e significação. São Paulo: Humanitas, 2001.

GREIMAS, A. J. Os atuantes, os atores e as figuras. In: CHABROL, C. Semiótica narrativa e textual. São Paulo: Cultrix, 1977. p.179-195.

. A enunciação: uma postura epistemológica. Significação: Revista Brasileira de Semiótica, Ribeirão Preto, n.1, p.09-25, 1974.

GREIMAS, A. J.; COURTÉS, J. Dicionário de semiótica. São Paulo: Contexto, 2008. 
HOUAISS, A.; VILLAR, M. de S. Dicionário Houaiss da Língua Portuguesa. Rio de Janeiro: Objetiva, 2001.

LANDOWSKI. E. A sociedade refletida: ensaios de sociossemiótica. São Paulo: EDUC: Pontes, 1992.

LEITE, R. L. Apontamentos para uma abordagem tensiva da metáfora. Estudos Semióticos, São Paulo, v.7, n.1, p.31-38, jun. 2011. Disponível em: <http://www.fflch. usp.br/dl/semiotica/es/eSSe71/2011esse71_rlleite.pdf >. Acesso em: 15 ago. 2012. MACIEL, R. Espelho. Diário do Nordeste, Fortaleza, 14 dez. 2007. Comunicado, p.4. PASCOWITCH,J.Aquário. Época, São Paulo,23 maio 2005. Quemacontece. Disponível em: <http://revistaepoca.globo.com/Revista/Epoca/0,EMI50335-15228,00.html>. Acesso em: 13 mar. 2010.

SARAIVA. J. A. B. Pessoal do Ceará: o percurso de uma identidade e a identidade de um percurso. 2008. 343f. Tese (Doutorado em Linguística) - Centro de Humanidades, Universidade Federal do Ceará, Fortaleza, 2008.

Recebido em 30 de setembro de 2011

Aprovado em 24 de novembro de 2012 
